\title{
Unconscious Bias or Deliberate Gatekeeping?
}

\author{
Louise Chapman, Filippo Contesi and Constantine Sandis \\ ask whether philosophy has a language problem
}

Philosophy has a language problem. A recent study by Schwitzgebel, Huang, Higgins and Gonzalez-Cabrera (2018) found that, in a sample of papers published in elite journals, $97 \%$ of citations were to work originally written in English. $73 \%$ of this same sample didn't cite any paper that had been originally written in a language other than English. Finally, a staggering 96\% of elite journal editorial boards are primarily affiliated with an Anglophone university. This is consistent with earlier data suggesting that journal submissions from countries that are outside the Anglophone world and Europe have disturbingly low chances of being accepted.

Unless one takes the absurd view that the data reflects who does the best philosophy and where they do it, this is prima facie cause for concern. The recently published "Barcelona Principles for a Globally Inclusive Philosophy" aim at addressing a "structural inequality between native and non-native speakers", and call on philosophers to take steps like including non-native speakers on editorial boards and not giving "undue weight to their authors' linguistic style, fluency or accent."

Schwitzgebel et al.'s study doesn't tell us what percentage of papers originally written in English were by non-native speakers. However, as Schwitzgebel's and others' data suggest, the academic pipeline of Anglophone philosophy is overwhelmingly self-confined within elite Anglophone institutions.

$$
\begin{aligned}
& \text { The academic pipeline of } \\
& \text { Anglophone philosophy } \\
& \text { is overwhelmingly } \\
& \text { self-confined within elite } \\
& \text { Anglophone institutions }
\end{aligned}
$$

Indeed, additional data point to a structural inequality between native and non-native speakers. For instance, preliminary data suggest that journal academic reviewing is in general biased against "non-nativelike English" prose and in fact non-native speakers of English appear to be much more poorly represented in prestigious philosophy departments than in equally prestigious scientific departments.

There is, then, a strong sense that, as the Barcelona Principles state, "non-native En- 


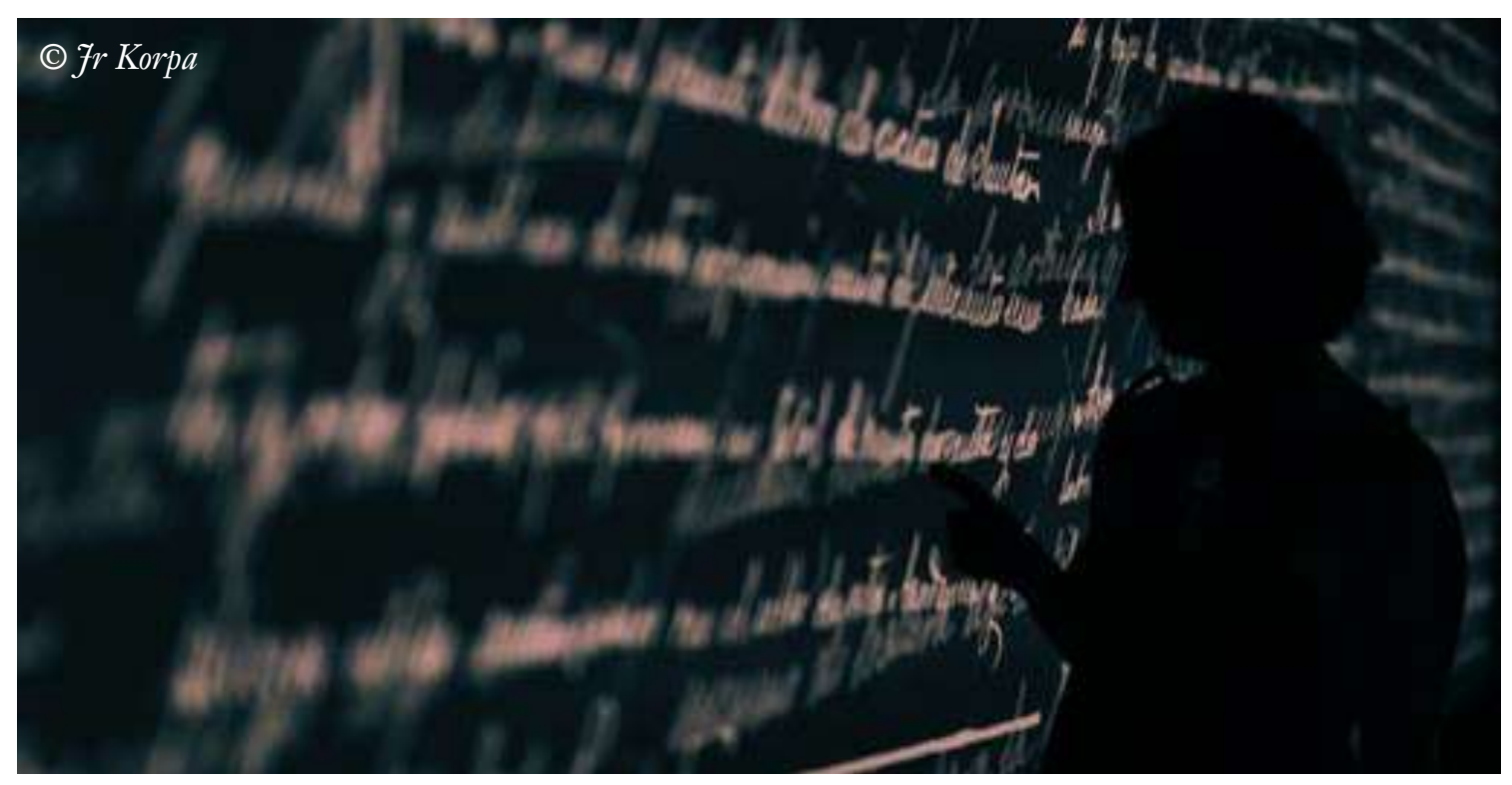

glish speakers, who have not had the chance to perfect their knowledge of the language, are at a structural disadvantage."

How can this disadvantage be explained?

It is possible that so-called "implicit biases" play a role here. Pantos and Perkins (2012) used the Implicit Association Test to measure implicit attitudes towards those who speak with 'foreign' accents, and similar associations may be at play when we encounter written work that we judge to be by a non-native speaker. However, over and above familiar worries about implicit attitudes, we should also be careful not to downplay the effects of more explicit evaluations of how a paper is written.

Here is an example. The Australasian Fournal of Philosophy invites referees to comment on whether papers "display flair, or elegance, or vivacity in the writing" and are "enjoyable, even exciting, to read". If the $A 7 P$ is unique, then it is only in making this requirement explicit: these instructions codify what happens, to a greater or lesser degree, when referees evaluate papers for top-tier journals.

Philosophy, then, has stylistic norms in addition to intellectual norms. Satisfying these former requirements will be harder for non-native speakers. As Ayala says in an earlier contribution to this conversation, it is likely both that writing in one's "native language gives one more freedom and control over one's written style", and that "stylistic considerations play a big role in editors' and referees' decisions." Indeed, the current system of peer-review that operates in philosophy is characterized by an extremely low acceptance rate, a very small number of editors who also hold normal academic jobs on the side, and publications of increasing length. The consequence of these factors is that a good number of prestigious journals are forced to make many desk decisions after reading only a few pages of, or skim-reading, the submissions they receive. This again makes one worry that superficial linguistic assessment of papers has a much bigger influence than it should.

What can be done to remedy the exclu- 
sionary effects of these stylistic, or aesthetic, criteria? Here are three broad approaches.

The first approach is to encourage a divergence from the common vehicular language model. Each philosopher would be writing in their native or preferred language. This, however, would risk engendering a "Tower of Babel problem". Such a problem might prove deleterious to philosophical progress, especially in the current interconnected world. Counter-balances to this problem could be widespread translation efforts, but those seem to be relatively unfeasible given the scarcity of resources currently available in philosophy.

The second, more divergent approach, expressed by the first of the aforementioned Barcelona Principles, is to reject the aforementioned stylistic norms, at least when making decisions that affect people's careers. Being elegantly written, according to this line of thought, does not in and of itself make for better philosophy. Allowing one's evaluations to be informed by such features therefore excludes certain philosophers on the basis of something other than the philosophical quality of their work. Rejecting these norms may involve telling reviewers not to attend to stylistic features of a paper (other than clarity), and ignoring such features when choosing papers to cite or add to reading lists. The extent to which one can consciously prevent our evaluations from being guided by some features is, of course, up for debate.

A third approach is to retain the stylistic norms but make it easier for non-native speakers to satisfy them. Increased access to developmental editorial support may be part of this approach. Again, practical questions persist. Wealthier scholars, from richer countries and better-funded faculties, have better access to such support. Funding could be provided as part of grants from governments or other institutions, or indeed by universities. This, however, excludes those who do not have grants, independent scholars, or those at less wealthy institutions. Moreover, the crisis of the current publishing model, amongst other things, means that those hoping for academic publishers to fund such services from their own profits may be waiting a long time.

The route forward is not entirely clear. What is clear, however, is that this structural disadvantage deserves closer philosophical and empirical attention. We owe this to current and future members of our philosophical community who speak English non-natively. We also need this if we want to make sure philosophy is enriched by a diverse group of thinkers who have a grasp of different languages, and of the cultures strongly associated with them.

Louise Chapman is CEO of author services firm, Lex Academic.

Filippo Contesi is Beatriu de Pinós Postdoctoral Fellow in the LOGOS Research Group in Analytic Philosophy, Universitat de Barcelona.

Constantine Sandis is Professor of Philosophy at the University of Hertfordshire and a Founding Director of Lex Academic. 